\title{
Nursing stress and satisfaction outcomes resulting from implementing a team nursing model of care in a rural setting
}

\author{
Linda Deravin*1, Karen Francis ${ }^{2}$, Sharon Nielsen ${ }^{3}$, Judith Anderson ${ }^{1}$ \\ ${ }^{1}$ School of Nursing, Midwifery and Indigenous Health, Charles Sturt University, Australia \\ ${ }^{2}$ School of Nursing, Midwifery \& Paramedicine, Australian Catholic University \& St John of God Health Care, Australia \\ ${ }^{3}$ Director Quantitative Consulting Unit, Charles Sturt University, Australia
}

Received: December 1, 2016

Accepted: January 29, 2017

Online Published: February 5, 2017

DOI: $10.5430 /$ jha.v6n1p60

URL: http://dx.doi.org/10.5430/jha.v6n1p60

\begin{abstract}
Objective: With increasing demands to provide a cost efficient nursing service, changes to nursing skill mix are being implemented globally. Team nursing as a model of care is seen as a way to address both patient care and safety issues. The aim of this study was to explore job satisfaction (JS) and stress outcomes of nursing staff when introducing team nursing as model of care within the Australian healthcare environment.

Methods: An experimental study was utilised. Nursing staff $(n=63)$ were surveyed, using the Person Centred Nursing Index (PCNI) tool, prior to the implementation of a team nursing model of care and then again six months post implementation of the model $(n=64)$. Data was analysed to determine if there was a statistically significant difference in the average theme between pre and post surveys.

Results: Nursing stress (NS) was reduced and JS was increased post implementation of the new model of care. JS and organisational traits, JS and work stress (WS), were positively related and increased post implementation. WS and nursing care (NC), organisational traits and $\mathrm{NC}$ were positively related but showed no statistically significant change after the implementation. This study demonstrated that in introducing a new model of care, levels of stress staff increased yet unexpectedly JS also improved. Conclusions: Decisions to adopt team nursing as the model of care should be based on a broad range of considerations not simply on fiscal considerations and should include staff readiness, staff mix and supportive measures to introduce a changed model of care.
\end{abstract}

Key Words: Job satisfaction, Job stress, Model of care, Team nursing, Team work

\section{INTRODUCTION}

With increasing demands to provide a cost efficient nursing service, varied classifications of nursing staff including registered nurses, enrolled nurses and assistants in nursing has been introduced into acute care health services for some time. $^{[1,2]}$ In Australia, registered nurses find themselves in a position of supervising other registered (including new graduate) and enrolled Nurses ${ }^{[3-5]}$ as well as other unregulated and non-credentialed health care workers. ${ }^{[5-7]}$

In order to manage the increased demands of responsibility and supervision of this range of varied staff classifications, team nursing as a model of care was introduced in five clini-

\footnotetext{
*Correspondence: Linda Deravin; Email: lderavin@csu.edu.au; Address: School of Nursing, Midwifery and Indigenous Health, Charles Sturt University, Australia.
} 
cal units medical/surgical in a rural region in Australia as a way to address this varied skill mix. A team nursing model of care in this context refers to all levels of nurses who contributed to the direct nursing care (NC) of patients including registered and unregistered staff. ${ }^{[7]}$ Team nursing requires personnel to work collaboratively to provide care to a group of patients under the supervision and direction of a registered nurse. ${ }^{[8]}$ The registered nurse acting as team leader assigns tasks, schedules care, and instructs team members in details of care. This paper reports on the findings of a study that introduced team nursing as a model of care in five clinical medical/surgical units in rural Australia and the impact this changed model of care had on nursing staff job satisfaction (JS) and levels of work related stress.

\section{BACKGROUND}

Nurses account for over $50 \%$ of health professionals in Australia with this figure increasing the more remote the context of practice. ${ }^{[9]}$ In rural and regional areas, the composition of the NC team in public acute care services is continuously evolving as new staff classifications are being introduced as a way to improve fiscal efficiencies and address a shortfall of Registered Nurses in rural areas. ${ }^{[1]}$ In metropolitan Australia numbers of Registered Nurses (1,000) per 100,000 head of population are higher than in regional (900) areas where the numbers of Enrolled Nurses are higher (20\% of regional nurses; $15 \%$ of metropolitan). ${ }^{[10]}$ This overall ratio is similar to data from previous years. ${ }^{[11]}$

Adopting models of care that capitalise on the skill mix of staff available is a feature of global contemporary nursing workplaces largely resulting from workforce shortage $e^{[4,6]}$ and desire to contain health care costs. ${ }^{[5,12]}$ In Australia, there are two levels of regulated nurses; registered and enrolled nurses. ${ }^{[1,13]}$ The Australian nursing workforce is ageing and has a large percentage of part-time employees. ${ }^{[11]}$ Increasingly, the nursing workforce is being supplemented by non-regulated nurses, nursing assistants as a method for ensuring appropriate staffing levels within a fiscally constrained environment. ${ }^{[4,6]}$ Health Workforce Australia [2014] presented options for reconfiguring the nursing workforce to ensure sustained NC. They suggested that unregulated nurses could represent $5 \%$ of the acute care sector and $70 \%$ of aged care workforce without a significant change in quality of care delivery. Any change to the nursing workforce skill mix however requires changes to work practices namely the models of care utilised to ensure quality care is upheld and public safety maintained. ${ }^{[4,6,14]}$ Ferdandez et al. ${ }^{[6]}$ and You et al. ${ }^{[15]}$ highlighted evidence that indicates best patient outcomes are achieved when the nursing workforce is primarily registered nurses. They conclude that registered nurses are the most highly qualified and are more likely to detect and respond to patient deterioration. Nonetheless, changing skill mix is heralded as the most likely method for addressing the predicted nurse shortage. It is therefore logical to suggest that in controlling health expenditure, that reconsidering models of care is inevitable. ${ }^{[5,6,11]}$

Health Workforce Australia ${ }^{[11]}$ temper Governments fiscal constraint commentary as a driver of health care change with a positive outcome for regulated nurses (registered nurses [RNs] and enrolled nurses [ENs]). They highlight scenarios that incorporate greater numbers of unregulated nurses which will improve opportunities for registered nurses and enrolled nurses to take on more complex practice activities that may support increased JS and reduce leakage from the system. Interestingly, predictions also highlight potential for oversupply of regulated nurses should graduate numbers increase. ${ }^{[11]}$

For many smaller rural and regional sites who operate on a one Registered Nurse model the concept of team nursing and its practical application is not new. ${ }^{[16]}$ However for larger regional hospitals where traditionally registered nurses represented the majority of the team, patient allocation models were appropriate. Fiscal pressures arising from spiralling costs of delivering health care and challenges related to recruitment and retention of nursing staff, prompted health services in rural areas to review existing models of NC. ${ }^{[17]}$ Increasingly, enrolled nurses (Level 2 regulated nurses) and Assistants in nursing (non-regulated health workers) have been identified by Health Workforce Australia ${ }^{[18]}$ as a viable way forward to reduce the cost of nursing services whilst maintaining a level of $\mathrm{NC}$ where recruitment of registered nurses is challenging. Changes to the scope of practice of enrolled nurse, such as medication endorsement, has enabled rethinking of traditional nursing skill mix models. A broader nursing skill mix is heralded as a cost effective strategy to address this workforce shortfall. ${ }^{[4,6]}$

Duffield, Roche, Diers, Catling-Paull and Blay ${ }^{[3]}$ undertook a study to look at nursing models of care and found that wards that had varied staffing skill mix adopted a team nursing model of care while wards with degree prepared and experienced nurses working on their usual ward utilised patient allocation. Patient allocation has been the usual model of care in acute care settings in Australia. ${ }^{[6,14]}$ This model of care traditionally utilises an almost exclusive $\mathrm{RN}$ workforce. In this model, nurses are allocated responsibility for the total care of a group of patients. ${ }^{[4,6]}$ In rural areas, an exclusive registered nurse workforce is not always available, therefore the need to adjust the model of care was initiated. Studies have highlighted improved staff satisfaction particularly of 
ENs; reduced sick leave enhanced retention and improved team spirit when a team nursing model of care is used. ${ }^{[6,19]}$

Team nursing is a preferred model of care when the team skill mix, qualifications, experience and expertise are diverse. ${ }^{[4,14]}$ This approach gained popularity in the $1950 \mathrm{~s}$ and has become a common choice more recently. ${ }^{[4,6]}$ Fairbrother et al. ${ }^{[4]}$ considered this model of care facilitates collaborative and cooperative work practices characterised by shared responsibility and accountability. Benefits of team nursing for patients include continuity of care; delivery of safer and better quality of care while benefits for nurses are enhanced working relationships and improved team dynamics. ${ }^{[14,20,21]}$ Studies have reported that team leaders who are generally experienced registered nurses find this model stressful. Recommendations to address this matter include supporting nursing staff to undertake leadership development education. ${ }^{[14]}$

Adopting team nursing as the model of care requires good leadership and communication between team members that must be prioritised if quality care is to be achieved. ${ }^{[14]}$ Orientation of nursing staff to team nursing, delineation of team and individual roles, clear protocols and continual engagement by management with nursing teams is necessary for effective implementation and ongoing sustainability of team nursing. ${ }^{[14]}$ Fernandez et al. ${ }^{[6]}$ commented that new graduate nurses and inexperienced nurses need support in their early years of practice. While the evidence is inconclusive it is likely that working within a team nursing model of care may accommodate the needs of these staff. Concerns have been raised however about diminishing RN numbers and the potential impact on supervision of student registered nurses as a consequence of widespread adoption of team nursing.

The aim of this study was to explore JS and stress outcomes of nursing staff when introducing team nursing as a model of care within the healthcare environment in rural New South Wales, Australia.

\section{METHOD}

An experimental design study (pre and post-test design) was utilised to establish if any cause and effect relationship existed between the variables. ${ }^{[5,22,23]}$ The sample of participants was drawn from five clinical medical/surgical units in three separate locations in rural New South Wales Australia. Nursing staff included registered nurses, enrolled nurse, assistants in nursing, nurse unit managers and clinical (ward based) nurse educators. Participants were surveyed using the Person Centred Nursing Index $(\mathrm{PCNI})^{[24]}$ pre and post implementation of a team nursing model of care. Participation in the study was voluntary. The type of work conducted within these clinical units remained constant. This survey was utilised to measure how the nurses felt about changing the way in which they administered their work through the changed model of care.

\subsection{Instrument}

This PCNI survey is a combination of the 76 question NCI and the 37 question Caring Dimension Index (CDI). ${ }^{[25]}$ The PCNI measures nurses' views about aspects of nursing work regardless of clinical specialty. It allows measurement of JS and stress through the grouping of questions in to relevant themes (domains). ${ }^{[26]}$ The survey was not revised and was used in its original form. A total of 113 questions were provided to nursing staff to complete. Each question was rated on a Likert scale from 1 to 7.

Questions were divided into the following themes:

1. Nursing stress (NS): Questions 1-19

2. Work stress (WS): Questions 20-36

3. Job satisfaction (JS): Questions 37-53

4. Organisational traits and outcomes (OT): Questions 54-76

5. Aspects of nursing care (NC): Questions 77-113

For NS and WS the value of 1 equated to no stress and the value of 7 was high stress. Within JS the value of 1 was low satisfaction up to a value of 7 which was high satisfaction. OT and aspects of NC the values were 1 being strongly disagree and 7 is strongly agree.

\subsection{Data collection}

Using the PCNI developed by Slater, McCormack and Bunting ${ }^{[24]}$ a paper based survey was distributed by ward managers to the nursing staff $(n=63)$ in the designated wards. Completion of the survey was purely voluntary. Surveys could be completed and returned reply paid envelopes directly to the central collator. The survey was administered prior to the implementation of the team nursing model of care, and then again $(n=64)$ six months post implementation of the model. As all surveys were completed anonymously there was no way to link pre and post surveys together by respondent. All anonymous paper based surveys were returned via post to a central collator who then analysed the data.

\subsection{Data analysis}

The responses were averaged across the range of questions within a theme to produce a theme average. The aim of the analysis was to determine if there was a significant difference in the average theme for both the pre and post surveys. This was done by using a one way analysis of variance model (Model 1) in ASReml-R, ${ }^{[27]}$ where Survey was the only fac- 
tor fitted within the model. Analysis of covariance methods (Model 2) was also used to explore the relationships between the themes, again using ASReml-R. ${ }^{[27]}$ The variance model assumptions are that the residuals are normally distributed, they have a constant variance and are independent. The factor level variances are equal for both surveys. The analysis of covariance model has the additional assumption that the covariate range must be similar for both surveys. All of the model assumptions were checked and met in this analysis. Pearson's correlation coefficients were used to determine the simple linear relationship between each of the themes and the hypothesis test was conducted to determine whether the correlation values are significantly different from zero or not. The usual 5\% significance level is used throughout this paper.

\subsection{Validity and reliability}

The PCNI has been previously used by other researchers and has been proven to be a valid tool when measuring staff satisfaction and stress levels within healthcare environments. ${ }^{[25,28]}$ To determine the reliability of the results in this study Cronbach's Alpha was applied. The overall Cronbach's Alpha value across all questions was 0.94 . The value for the themes overall is provided in the Table 1.

Cronbach's Alpha in responding to the items across all themes was greater than 0.89 . This represents a good to excellent consistency in the scoring among participants. ${ }^{[29,30]}$

\subsection{Ethical considerations}

All participants in the study were anonymous and completion of the study was voluntary. No data could be linked to any one participant either pre or post intervention. The researchers had no pre-existing relationships with any of the respondents. In accordance with local regulations, approval for the study was provided by the local institutional review authority which determined that the study did not need formal human ethics and research approval and was therefore exempt. The study was undertaken as part of a quality improvement program.

\section{RESULTS}

All classifications of nursing staff working in the targeted clinical units were invited to participate. No demographic data, regarding age distribution, education levels and qualifications were collected. A total of 127 surveys were completed in the study with an overall response rate of $52 \%$. The response rate of surveys completed prior to the implementation of the model of care was $53 \%$ and post implementation was $50 \%$. The survey was distributed to both male and female staff aged between 18 to 65 years, however this was not considered significant for the results of this study. A summary of themes and results from the one way analysis of variance is shown in Table 2.

\subsection{NS}

NS results pre intervention survey showed a data range between 2.3 minimum to 5.3 maximum with a standard deviation of 0.85 and a mean of 3.5 and post intervention survey were between 1.4 minimum to 5.1 maximum, standard deviation was 0.85 and the mean was 3.2. The median post intervention was lower than the median pre intervention survey, however the spread of the responses was larger for the post intervention survey. There was no significant difference in the average response for pre and post intervention as the Model $1 p$-value was $>.05$. However there was a significant difference in the average response for the pre and post survey at the $10 \%$ significant level.

Table 1. Cronbach's Alpha

\begin{tabular}{llll}
\hline Theme & Sample Size & Number of Items & Alpha \\
\hline JS & 127 & 18 & 0.91 \\
NC & 127 & 35 & 0.91 \\
NS & 127 & 19 & 0.91 \\
OT & 127 & 24 & 0.89 \\
WS & 127 & 17 & 0.94 \\
\hline
\end{tabular}

Note. JS: job satisfaction; NC: nursing care; NS: nursing stress; OT: organisational traits and outcomes; WS: work stress

Table 2. Data summary and one way analysis of variance results

\begin{tabular}{|c|c|c|c|c|c|c|c|c|c|c|c|}
\hline Theme & Survey & $n$ & Minimum & Mean & Median & Maximum & $\begin{array}{l}\text { Standard } \\
\text { Deviation }\end{array}$ & $\begin{array}{l}\text { lower } \\
\text { confidence level }\end{array}$ & $\begin{array}{l}\text { upper } \\
\text { confidence level }\end{array}$ & $F$ & Sig \\
\hline \multirow{2}{*}{ NS } & Pre & 63 & 2.3 & 3.5 & 3.4 & 5.3 & 0.85 & 1.10 & 5.88 & \multirow{2}{*}{3.53} & \multirow{2}{*}{.062} \\
\hline & Post & 64 & 1.4 & 3.2 & 3.1 & 5.1 & 0.85 & 0.82 & 5.59 & & \\
\hline WS & Post & 64 & 1.1 & 2.7 & 2.6 & 4.8 & 0.99 & 0.43 & 5.06 & 2.06 & .154 \\
\hline \multirow{2}{*}{ JS } & Pre & 63 & 2.9 & 4.3 & 4.4 & 5.5 & 0.78 & 1.87 & 6.75 & \multirow{2}{*}{4.51} & \multirow{2}{*}{.036} \\
\hline & Post & 64 & 1.8 & 4.7 & 4.8 & 6.7 & 1.06 & 2.37 & 6.95 & & \\
\hline \multirow{2}{*}{ OT } & Pre & 63 & 2.5 & 4.1 & 4.2 & 5.3 & 0.74 & 1.66 & 6.60 & \multirow{2}{*}{0.44} & \multirow{2}{*}{.507} \\
\hline & Post & 64 & 1.5 & 4.2 & 4.3 & 6.1 & 0.93 & 1.88 & 6.58 & & \\
\hline \multirow{2}{*}{$\mathrm{NC}$} & Pre & 63 & 3.7 & 5.2 & 5.3 & 5.9 & 0.48 & 2.39 & 8.09 & \multirow{2}{*}{0.11} & \multirow{2}{*}{.746} \\
\hline & Post & 64 & 3.1 & 5.3 & 5.3 & 6.4 & 0.62 & 2.68 & 7.86 & & \\
\hline
\end{tabular}

Note. NS: nursing stress; WS: work stress; JS: job satisfaction; OT: organisational traits and outcomes; NC: nursing care 


\subsection{WS}

WS results pre intervention survey showed a data range between 1.1 minimum to 5.2 maximum with a standard deviation of 1.11 and a mean of 3.0. The post intervention survey was between 1.1 minimum to 4.8 maximum, standard deviation was 0.99 and the mean was 2.7. The median post intervention was lower than the median pre intervention survey, however the spread of the responses was smaller post intervention survey. There was no significant difference in the average response for pre and post intervention as the Model $1 p$-value was $>.05$.

\subsection{JS}

JS results pre intervention survey showed a data range between 2.9 minimum to 5.5 maximum with a standard deviation of 0.78 with a mean of 4.3. The post intervention survey was between 1.8 minimum to 6.7 maximum, standard deviation was 1.06 and the mean was 4.7. The median post intervention survey was higher than the median pre intervention survey, however the spread of the responses was larger post survey. There was a significant difference in the average response for pre and post intervention as the Model 1 $p$-value $=.036$.

\subsection{OT}

OT results pre intervention survey showed a data range between 2.5 minimum to 5.3 maximum with a standard deviation of 0.74 and a mean of 4.1. The post intervention survey was between 1.5 minimum to 6.1 maximum, standard deviation was 0.93 and the mean was 4.2. The median post intervention was approximately the same as the median pre intervention survey, however the spread of the responses was larger post survey. There was no significant difference in the average response for pre and post intervention as the Model $1 p$-value was $>.05$.

\subsection{Aspects of NC}

Aspects of $\mathrm{NC}$ results pre intervention survey showed a data range between 3.7 minimum to 5.9 maximum with a standard deviation of 0.48 and a mean of 5.2. The post intervention survey was between 3.1 minimum to 6.4 maximum, standard deviation was 0.62 and the mean was 5.3. The median post intervention was approximately the same as the median pre intervention survey, however the spread of the responses was larger post survey. There was no significant difference in the average response for pre and post intervention as the Model $1 p$-value was $>.05$.

\subsection{Relationships between the themes}

There appear to be positive linear relationships between OT and JS, OT and NC, JS and NC, and NS and WS having
Pearson's Correlation coefficients $r=0.64,0.65,0.42$ and 0.40 respectively ( $p$-value $<.05$ ). These relationships were explored further using Table 2 , accounting for the pre- and post-survey results.

There is a curvilinear relationship between WS and NS $(p$-value <.05). There is also a significant difference in the NS results for the pre and post survey, as WS increases the average NS also increases up until WS reaches a level of 4 units. From 4 to 5 NS plateaus and starts to decrease.

There is a linear relationship and JS and OT $(p$-value <.001) and a significant difference between the JS results in pre and post survey $(p$-value $=.007)$. As OT increases by 1 unit JS increase by 0.72 . Post survey the JS values are higher across all OT values compared to pre survey. NC is related to WS ( $p$-value $<.001)$ and were the same both pre and post survey on these variables. A linear relationship JS and NC ( $p$-value $<.001)$. JS was higher post survey across all WS levels compared to pre survey. There was a significant linear relationship between OT and NC ( $p$-value $<.001)$, for every unit increase in NC OT increases by 0.92 , there were no difference pre and post-test for this relationship.

\section{Discussion}

Stress can exist within any workplace yet nursing has been recognised as having its own inherent level of stress. ${ }^{[31]}$ Within this survey two areas of stress were examined being WS and nurse stress. In this context, NS related to the amount of nursing work or patient load the nurse was responsible for, aspects of $\mathrm{NC}$ directly related to the delivery of $\mathrm{NC}$ for the patient and feeling prepared to perform the nursing role. WS considered factors such as; work life balance and the support from family and social networks, appreciation of work provided by nurses from patients and other staff, the ability to communicate with other staff and the variety of work provided, and the opportunity for career development.

This study demonstrated that implementing the team nursing model of care did not change how staff perceived aspects of NC they provided, organisational supports or the level of work related stress. However it did show an increase in NS which was an expectation when implementing any change to practice. Assumptions made by the researchers that work related stress would decrease JS were not proven. In fact this study demonstrated that there was an increase in JS related to the new model of care.

Changes to the practice environment such as adopting new models of care can be confronting to nurses. However, as demonstrated in this study sufficient support provided by the organisation has a positive effect on the level of stress experienced by those undergoing a change process. Evidence 
indicates that the workplace environment is critical to nurses' perceptions of JS. ${ }^{[12,32,33]}$ With these changes in the model of care the workload was more evenly distributed amongst the staff. This increased the JS of the staff who participated in this survey, overcoming issues as identified by Sprinks ${ }^{[34]}$ of increasing workload which has a direct effect on burnout and fatigue. If nurses feel valued, in control, listened to, believe the organisation is flexible, and are provided with career opportunities they are more likely to remain in the workforce ${ }^{[5,11,12,33]}$ and are less likely to develop debilitating conditions such as compassion fatigue, secondary traumatic stress disorder, anxiety, depression, stress and burnout. ${ }^{[13]}$ Hegney et al. ${ }^{[13]}$ argued that these conditions impact adversely on nurse attrition rates and increase costs for the employer. Working with nursing staff, seeking their feedback, listening and responding to their issues are necessary actions for any employer concerned for staff wellbeing and the overall operation of their organisation. Good management that is staff and customer focussed is critical, particularly in health related workplaces where staff performance has a direct impact on patient outcomes.

\section{Limitations}

Limitations of this study include a small sample size, however this is reflective of staffing numbers in rural areas, no differentiation in job classifications both pre and post survey collected within the survey, and that this study was conducted in only one rural geographical area. There was no way to identify if the same participants completed both the pre and post survey as this was conducted anonymously. The only criteria for participation was being part of the nursing staff which included both regulated and unregulated staff such as registered nurses, enrolled nurse, assistants in nursing, nurse unit managers and clinical (ward based) nurse educators. Nursing staff participating in the survey must have been working in the five designated clinical medical/surgical units where this model of care was introduced.

\section{Conclusions}

It is acknowledged that team nursing is a useful model of care when skill mix is varied. Decisions to adopt team nursing as the model of care should be based on a broad range of considerations not simply on fiscal considerations and should include staff readiness, staff mix and supportive measures to introduce a changed model of care. This study demonstrated that in introducing a new model of care, increased levels of stress within nursing staff which was an expected outcome. Simultaneously this study showed that JS improved which was an unexpected phenomena. No other differences in levels of satisfaction or stress were identified. It is important to note that when seeking to introduce change within the workplace, staff who feel valued, involved and supported in the introduction of the change may have a positive effect on staff outcomes.

\section{CONFliCtS OF INTEREST Disclosure}

The authors declare they have no conflict of interest.

\section{REFERENCES}

[1] Health Workforce Australia. National health workforce innovation and reform strategic framework for action 2011-2015. Adelaide; 2011.

[2] Duffield C, Diers D, O'Brien-Pallas L, et al. Nursing staffing, nursing workload, the work environment and patient outcomes. Applied Nursing Research. 2011; 24(4): 244-55. https://doi.org/10.1 016/j.apnr.2009.12.004

[3] Duffield C, Roche M, Diers D, et al. Staffing, skill mix and the model of care. Journal of Clinical Nursing. 2010; 19(15-16): 2242-51. https://doi.org/10.1111/j.1365-2702.2010.03225.x

[4] Fairbrother G, Jones A, Rivas K. Changing model of nursing care from individual patient allocation to team nursing in the acute inpatient environment. Contemporary Nurse. 2010; 35(2): 202-20. https://doi.org/10.5172/conu.2010.35.2.202

[5] Jacob ER, McKenna L, D'Amore A. The changing skill mix in nursing: Consideration for and against different levels of nurse. Journal of Nursing Management. 2015; 22(4): 506-18. https: //doi.org/10.1111/jonm. 12162

[6] Fernandez R, Johnson M, Tran DT, et al. Models of care in nursing: a systematic review. International Journal of Evidence-Based Health- care. 2012; 10(4): 324-37. https://doi.org/10.1111/j.1744 $-1609.2012 .00287 . \mathrm{x}$

[7] Tran DT, Johnson M, Fernandez R, et al. A shared care model vs. a patient allocation model of nursing care delivery: Comparing nursing staff satisfaction and stress outcomes. International Journal of Nursing Practice. 2010; 16(2): 148-58. https://doi.org/10.1111/j. 1440-172X.2010.01823.x

[8] Marquis BL, Houston CJ. Leadership roles and management functions in nursing. 7th ed. Philadelphia: Lippincott Williams and Wilkins; 2012.

[9] Hegney D, Francis K, Mills J. Rural health. In: Frncis K, Chapman Y, Davies C, editors. Rural nursing: The Australian contexr Port Melbourne: Cambridge Press; 2014. 18-33 p.

[10] Australian Institute of Health and Welfare. How many nurses and midwives are there? Canberra: AIHW; 2016 [cited 2016 6/8]. Available from: http://www.aihw.gov.au/workforce/nursing-a nd-midwifery/how-many/

[11] Health Workforce Australia. Australia's future health workforce Nurses overview report. Canberra: Department of Health; 2014.

[12] Aiken LH, Sloane DM, Bruyneel L, et al. Nurses' reports of working conditions and hospital quality of care in 12 countries in Eu- 
rope. International Journal of Nursing Studies. 2013; 50(2): 143-53. https://doi.org/10.1016/j.ijnurstu. 2012.11.009

[13] Hegney D, Graigie M, Hemsworth D, et al. Compassion satisfaction, compassion fatigue, anxiety, depression and stress in registerd nurses in Australia: Study 1 results. Journal of Nursing Management. 2013; 22 (4): 506-18. PMid: 24175955. https: //doi.org/10.1111/jonm. 12160

[14] Ferguson L, Cioffi J. Team nursing: experiences of nurse managers in acute care settings. Australian Journal of Advanced Nursing. 2011; 28(4): 5-11.

[15] You LM, Aiken LH, Sloane DM, et al. Hospital nursing, care quality, and patient satisfaction: Cross-sectional surveys of nurses and patients in hospitals in China and Europe. International Journal of Nursing Studies. 2013; 50(2): 154-61. https://doi.org/10.101 6/j.ijnurstu.2012.05.003

[16] Anderson J, Bonner A, Grootjans J. Collaboration: developing integration in multipurpose services in rural New South Wales, Australia. Rural \& Remote Health. 2011; 11(4). PMid: 22149645.

[17] Malone LM, Anderson JK. The right staffing mix for inpatient care in rural multi-purpose service health facilities. Rural Remote Health. 2014; 14(4): 2881. PMid: 25455927.

[18] Health Workforce Australia. Health Workforce Australia 2012-13 work plan final version. Adelaide; 2012.

[19] Kirwan M, Matthews A, Scott PA. The impact of the work environment of nurses on patient safety outcomes: A multi-level modelling approach. International Journal of Nursing Studies. 2013; 50(2): 25363. https://doi.org/10.1016/j.ijnurstu. 2012.08.020

[20] Cioffi J, Ferguson L. Team nursing in acute care settings: Nurses' experiences. Contemporary Nurse. 2009; 33(1): 2-12. PMid: 19715490. https://doi.org/10.5172/conu.33.1.2

[21] O'Connell B, Duke M, Bennett P, et al. The trials and tribulations of team-nursing. Collegian. 2006; 13(3): 11-7. https: //doi .org/10 .1016/S1322-7696(08)60527-2

[22] Sousa VD, Driessnack M, Mendes IAC. An overview of research designs relevant to nursing: Part 1: quantitative research designs. Revista Latino-Americana de Enfermagem. 2007; 15: 502-7. PMid: 17653437. https ://doi.org/10.1590/S0104-1169200 7000300022

[23] Brink PJ, Wood M, editors. $2^{\text {nd }}$ ed. California: Sage Publications; 1998.

[24] Slater P, McCormack B, Bunting B. The Development and Pilot Testing of an Instrument to Measure Nurses' Working Environment:
The Nursing Context Index. Worldviews on Evidence-Based Nursing. 2009; 6(3): 173-82. https://doi.org/10.1111/j.1741-6787. 2009.00159.x

[25] McCance T, Slater P, McCormack B. Using the caring dimensions inventory as an indicator of person-centred nursing. Journal of Clinical Nursing. 2009; 18(3): 409-17. https://doi.org/10.1111/j.13 65-2702.2008.02466.x

[26] White C, Wilson V. A longitudinal study of aspects of a hospital's family-centred nursing: changing practice through data translation. Journal of Advanced Nursing. 2015; 71(1): 100-14. https: //doi.org/10.1111/jan.12478

[27] Butler DG, Cullis BR, Gilmour AR, et al. Analysis of mixed models for s-language environments: Asreml-r reference manual Brisbane: Qld Department of Primary Industries and Fisheries; 2007.

[28] Slater P, O'Halloran P, Connolly D, et al. Testing of the Factor Structure of the Nursing Work Index-Revised. Worldviews on EvidenceBased Nursing. 2010; 7(3): 123-34. https://doi.org/10.1111/ j.1741-6787.2009.00158.x

[29] Tavakol M, Dennick R. Making sense of Cronbach's alpha. International journal of medical education. 2011; 2: 53. PMid: 28029643. https://doi.org/10.5116/ijme.4dfb.8dfd

[30] Watson R, Lea A. The caring dimensions inventory (CDI): content validity, reliability and scaling. Journal of Advanced Nursing. 1997; 25(1): 87-94. https://doi.org/10.1046/j.1365-2648.1997 $.1997025087 . x$

[31] Wright K. Alleviating stress in the workplace: advice for nurses. Nursing Standard. 2014; 28(20): 37-42. https ://doi .org/10.7 $748 / \mathrm{ns} 2014.01 \cdot 28 \cdot 20 \cdot 37 . \mathrm{e} 8391$

[32] Lake ET, Friese CR. Variations in nursing practice environments: relation to staffing and hospital characteristics. Nursing Research. 2006; 55(1): 1-9. https://doi.org/10.1097/00006199-200601000 $-00001$

[33] Twigg D, McCullough K. Nurse retention: a review of strategies to create and enhance positive practice environments in clinical settings. International journal of nursing studies. $2014 ; 51(1)$ : $85-$ 92. PMid: 23809644. https://doi.org/10.1016/j.ijnurstu .2013 .05 .015

[34] Sprinks J. An ever-increasing workload is causing burnout and exhaustion: unrelenting cost reductions in the NHS are taking their toll in Wales, with a sharp rise in the number of nurses on stress-related sick leave. Nursing Standard. 2012; 26: 12. https : //doi.org/10.7748/ns2012.02.26.26.12.p7697 